\title{
More than 50 UK Zika cases are reported in people returning from abroad so far this year
}

\author{
Susan Mayor \\ London
}

Public Health England says that more than 50 people in the United Kingdom have had Zika virus infection diagnosed after travelling abroad so far this year, in a statement issued after new cases were reported this week in Calderdale and Huddersfield NHS Foundation Trust, West Yorkshire.

Paul Cosford, medical director at Public Health England, said, "We expect to see small numbers of Zika virus infections in travellers returning to the $\mathrm{UK}$, but the risk to the wider population is very low, as the mosquito that spreads the Zika virus is not found in the UK.

"As of 27 July 2016, over 50 cases have been diagnosed in UK travellers since January 2016. Public Health England is monitoring the international situation closely, and the risk to the UK remains unchanged."

He advised that people returning from an area where Zika virus transmissions are currently reported and who have a fever or flu-like illness should "seek medical attention without delay to exclude malaria and [should] mention your recent travel."

Three cases of Zika virus infection were reported by Calderdale and Huddersfield NHS Foundation Trust in an infection control report to the organisation's trust board meeting this week (28 July), local newspapers said. The trust reportedly said, "Three patients have tested positive for Zika virus following return from foreign travel." Public Health England confirmed that new cases of Zika virus infection had been reported in Yorkshire.

Gavin Boyd, infection control lead for the trust, said in a statement, "There is no specific treatment, and it wears off naturally after two to seven days. After a diagnosis patients are cared for by their GPs."

He added, "There is extremely low risk of contracting Zika virus in the UK, as the mosquito that transmits the virus is not present in the UK. A small number of cases of sexual transmission globally have been reported, but the risk is very, very small." Guidance from Public Health England for UK GPs notes that symptoms and signs of clinical illness caused by Zika include rash, itching/pruritus, fever, headache, arthralgia/arthritis, myalgia, conjunctivitis, lower back pain, and retro-orbital pain. ${ }^{1}$ Symptomatic Zika infection is typically a mild and self limiting illness, but the guidance advises that clinicians should also consider in their differential diagnosis other travel associated infections including dengue and chikungunya virus infections, malaria, common infections, and non-infectious diseases.

Public Health England recommends that pregnant women who have travelled to an area with active Zika transmission during their pregnancy, who report clinical illness that raises suspicion of Zika during or within two weeks of travel and who are currently symptomatic, should be tested for Zika infection and should have a baseline fetal ultrasound examination after referral to a local antenatal ultrasound service.

1 Public Health England. Zika virus infection: guidance for primary care. 16 Jun 2016. https: //www.gov.uk/government/uploads/system/uploads/attachment_data/file/529984/Zika_ virus_guidance_for_primary_care_v6.pdf.

Published by the BMJ Publishing Group Limited. For permission to use (where not already granted under a licence) please go to http://group.bmj.com/group/rights-licensing/ permissions 